\title{
DESENVOLVIMENTO DE MODELOS QUALITATIVOS PARA 0 ENSINO DE ESTRUTURAS
}

\section{DEVELOPING QUALITATIVE MODELS FOR STRUCTURAL LEARNING}

\author{
Tales Lobosco ${ }^{1}$ \\ Universidade Federal de Minas Gerais, Belo Horizonte, MG, Brasil, tales@lobosco.com.br \\ Débora Carvalho Câmara ${ }^{2}$ \\ Universidade Federal de Minas Gerais, Belo Horizonte, MG, Brasil, d.carvalhocamara@outlook.com
}

\begin{abstract}
Resumo
A utilização de modelos qualitativos em escala reduzida se apresenta como uma importante ferramenta no ensino de estruturas por permitir a compreensão do comportamento mecânico, através da observação das deformações apresentadas pelo modelo de maneira intuitiva e clara. Neste sentido, este trabalho se desenvolve a partir da análise e discussão dos modelos qualitativos didáticos existentes e demonstra o desenvolvimento de um modelo qualitativo simples, e de baixo custo, que seja capaz de promover uma compreensão intuitiva do comportamento mecânico das estruturas e que possua boa flexibilidade de montagens para permitir a exploração de diversas possibilidades estruturais. A proposta é que este modelo possa servir como uma ferramenta de aprendizado e experimentação, permitindo a visualização do comportamento mecânico das estruturas, evidenciando as deformações, torções e flechas apresentadas, de maneira a permitir a correlação da experiência intuitiva dos fenômenos observados com as simulações numérico-computacionais tradicionalmente realizadas no processo de concepção estrutural. Por fim o artigo apresenta os resultados obtidos, nos quais o modelo desenvolvido se mostrou bastante promissor, permitindo um primeiro contato com o comportamento estrutural além de permitir uma boa exploração qualitativa das montagens estruturais experimentadas.
\end{abstract}

Palavras-chave: Modelos Estruturais. Sistemas Estruturais. Ensino de Estruturas.

\begin{abstract}
The use of qualitative models in small-scale presents itself as an essential tool for teaching structural systems as it allows the direct observation of the deformations in the model, therefore promoting the understanding of the mechanical behavior in an intuitive and clear way. In this sense, this work develops an analysis of the existing didactic qualitative models aiming the development of a simple and low-cost qualitative model that should be capable of promoting an intuitive understanding of the mechanical behavior of the structures and, at the same time, presents enough flexibility to allow the experimentation of various structural possibilities. This model proposes to serve as a tool for learning through the visualization of the mechanical behavior of the structures. The observation of the deformations, twists, and arrows may allow the correlation of the intuitive experience of the phenomena with the numerical simulations traditionally carried out in the process of structural design. Finally, the article presents the results obtained, in which the developed model proved itself to be very promising, promoting a rich first contact with the structural behavior besides a good qualitative exploration of the structural possibilities.
\end{abstract}

Keywords: Structural Models. Structural Systems. Structural Learning.

How to cite this article:

LOBOSCO, Tales; CÂMARA, Débora Carvalho. Desenvolvimento de modelos qualitativos para o ensino de estruturas. PARC Pesquisa em Arquitetura e Construção, Campinas, SP, v. 9, n. 3, p. 167-178, set. 2018. ISSN 1980-6809. Disponível em:

$<$ <ttps://periodicos.sbu.unicamp.br/ojs/index.php/parc/article/view/8650263>. Acesso em: 16 set. 2018.

doi:https://doi.org/10.20396/parc.v9i3.8650263. 


\section{Introdução}

O uso de simulações, sejam a partir de modelos físicos ou métodos numéricos, permite prever o comportamento de estruturas e simular o comportamento de um sistema antes de efetivamente construí-lo. Esta antecipação abriu caminho para um grande avanço nos processos construtivos e soluções estruturais.

Assim, os processos de concepção estrutural contam com a simulação numérica para testar o comportamento das propostas previamente concebidas (SARAMAGO, 2011), validando ou indicando a necessidade de correções. $\mathrm{Ou}$ seja, somos capazes de evitar problemas, otimizar o dimensionamento e permitir avanços construtivos, que seriam impossíveis empiricamente.

Adicionalmente, também podemos utilizar ambientes computacionais avançados que permitam a experimentação exploratória de estruturas, auxiliando profundamente no processo de concepção.

Entretanto, esse ferramental não prescinde de um profundo conhecimento prévio sobre o comportamento mecânico das estruturas. E, segundo Hossdorf (1974) o comportamento dos sistemas estruturais, como qualquer fenômeno físico, pode ser compreendido por meio da observação direta, pela simulação produzida na compreensão da teoria ou por experimentos e modelos físicos.

Conforme Margarido (2003), é nesta situação que os modelos qualitativos podem atuar mais ativamente: eles possuem a qualidade de nos fazer visualizar as flechas e as rotações que ocorrem em uma estrutura, permitindo que este comportamento se torne evidente aos nossos sentidos.

Deste modo, a proposta do trabalho é o desenvolvimento de um modelo qualitativo didático em escala reduzida, que possa promover uma primeira aproximação dos alunos com o comportamento mecânico dos sistemas estruturais através da visualização das deformações apresentadas pelas estruturas.

Por fim, a proposta do modelo didático não busca a produção de uma ferramenta para substituir os procedimentos tradicionais de concepção estrutural, mas uma forma de estimular o aprendizado intuitivo dos comportamentos estruturais, ou seja, um modelo para ser utilizado em processos de experimentação qualitativos, estimulando a compreensão intuitiva e auxiliando o aluno a relacionar o comportamento mecânico observado nos modelos físicos com a aplicação dos modelos numéricocomputacionais.

\section{Modelos Físicos}

Um modelo físico em escala reduzida se apresenta como uma ferramenta a ser adotada para identificar, de maneira simples, se será possível, ou não, alcançar um equilíbrio, mantendo-se as proporções determinadas (TORROJA, 1957). Segundo Harris e Sabnis (1999) estes modelos físicos podem ser classificados a partir de suas características e das finalidades a que se destinam.

Para o propósito deste artigo podemos ressaltar dois tipos básicos:

O Modelo Qualitativo, ou elástico, elaborado a partir da semelhança geométrica direta com a estrutura proposta, mas produzido com material homogêneo sem necessariamente reproduzir as características e especificidades dos materiais originais. Os modelos qualitativos são restritos às situações de comportamento elástico dos protótipos, não sendo indicados, portanto, para evidenciar os modos de colapso das estruturas.

Esses modelos apresentam certa flexibilidade construtiva, pois são construídos para a observação da mecânica estrutural a partir de suas deformações, logo, precisam ser capazes de evidenciar o comportamento estrutural através da visualização das deformações apresentadas pela montagem.

O Modelo de Esforço, ou modelo realístico, construído com materiais similares à estrutura proposta, de maneira que se possa prever o comportamento estrutural e as reações ao carregamento. São modelos elaborados com grande preocupação construtiva e realística. Afinal, para seu correto funcionamento, é preciso se certificar que as forças variem de maneira homotética ao longo da escala da construção.

\section{Modelos Qualitativos no Ensino de Estruturas}

A grande complexidade de algumas obras contemporâneas, associada ao grande desenvolvimento das tecnologias digitais e a disponibilidade de ambientes computacionais paramétricos, torna inevitável o emprego de sofisticados programas computacionais no processo de simulação e concepção estrutural

Entretanto, segundo Schodeck e Bechthold (2015), a concepção estrutural, seja através da verificação por simulação numérica, quanto através da utilização de técnicas de simulação virtual interativa demanda um conhecimento aprofundado do comportamento e das condições de equilíbrio de uma estrutura e de suas partes.

É neste caminho que os modelos físicos qualitativos se inserem no processo de aprendizagem: ao promover um primeiro contato dos alunos com o comportamento 
mecânico das estruturas através de uma experiência vivenciada e empírica, eles abrem caminho a uma compreensão mais ampla e intuitiva do comportamento estrutural, capaz de romper a aversão dos alunos às simulações matemáticas.

Pier Luigi Nervi (1951) defende que um aluno que tenha visto a atuação de um fenômeno com seus próprios olhos chegará muito mais facilmente a uma compreensão clara e ampla das relações estáticas-estruturais, condição indispensável para a invenção estrutural. Embora defenda os avanços da matemática na concepção, Nervi destaca a importância do caminho experimental que substitui o percurso teórico realizado através de "inevitáveis aproximações e simplificações" pela observação direta do estado de equilíbrio de uma estrutura (NERVI, 1951, p.21).

Assim, o processo de aprendizagem do comportamento estrutural conduzido com o suporte de modelos qualitativos, através da visualização das deformações no modelo físico, ajudaria $\mathrm{o}$ aluno a relacionar $\mathrm{o}$ comportamento mecânico estrutural com o modelo numérico-computacional utilizado para concepção e simulação das estruturas.

Esta aprendizagem vivenciada e intuitiva dos comportamentos estruturais elementares também seria muito útil para uma concepção arquitetônica mais integrada ao funcionamento estrutural do edifício. Neste sentido, Franco (1974) já defendia o uso de modelos qualitativos simples como forma de se buscar esta integração.

Historicamente, podemos identificar a origem do uso de modelos qualitativos em ambiente didático com Rathbun, em 1934, através da simulação do comportamento de vigas a partir de peças de borracha e do uso de blocos de madeira amarrados em uma corda para demonstrar como um arco se ajusta sob ação de uma carga distribuída, e como reage quando submetido a cargas concentradas (HARRIS; SABNIS, 1999).

A praticidade que esta abordagem apresenta, aliada ao fato de serem bastante intuitivos na representação de determinadas situações, fez com que diversos modelos simples, e até certo ponto improvisados, fossem largamente utilizados nas salas de aula, para transmitir os conceitos básicos da engenharia estrutural.

Alguns destes exemplos foram tão amplamente difundidos que acabaram sendo reproduzidos por diversos autores. Assim, podemos encontrar o uso de folhas de papel abertas, em arco ou dobradas - demonstrando as propriedades da forma na atuação das estruturas em livros como Allen e Zalewski (2010) e Rebello (2000). Também encontraremos o uso de réguas para a demonstração da influência das dimensões em uma viga e da ação da flambagem em pilares, em livros como Evans, Silver e Mclean (2009) e Salvadori (1990).

Estes modelos iniciais deram espaço ao surgimento de experimentações um pouco mais elaboradas como a de Salvadori (1990), que propõe a aplicação de uma camada de fita adesiva ao longo da face de uma barra alongada de espuma, para que seja possível visualizar a atuação da armadura metálica em uma estrutura de concreto (Figura 1), em seguida contrapõe o experimento a uma situação similar, mas, desta vez, estruturada pelo formato da peça.

Figura 1 - Modelos com enrijecimento por simulação de armadura (fita) ou pelo formato
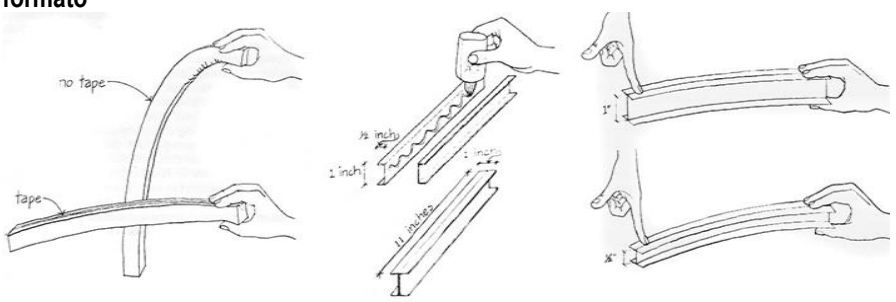

Fonte: Salvadori, 1990

No mesmo caminho, autores como Evans, Silver e Mclean (2009) exploram as correlações com o corpo humano e a possibilidade de recriação destas estruturas e esforços, se utilizando dos próprios alunos (Figura 2).

Figura 2 - 0 corpo como modelo estrutural

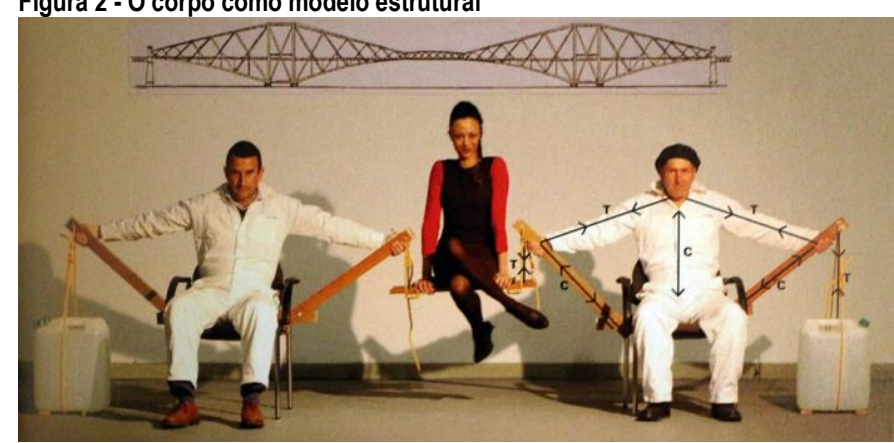

Fonte: Evans, Silver e Mclean (2009)

Com a mesma intenção didática dos modelos qualitativos, autores como Engel (2001), Torroja (1957), Rebello (2000) e Schodek; Bechthold (2015) se utilizam de desenhos simplificados, acentuando a atuação das forças e de modo a enfatizar as deformações apresentadas na estrutura, para permitir a visualização do comportamento do sistema (Figura 3).

A representação conceitual através de desenhos traz uma abordagem bastante eficiente para a visualização das deformações, mas não permite a manipulação dos elementos ou dos esforços, limitando a experiência intuitiva da ação da estrutura. E, principalmente, não permite a recombinação exploratória dos esquemas, limitando sua ação como uma ferramenta de concepção 
Figura 3 - Desenho estruturais didáticos
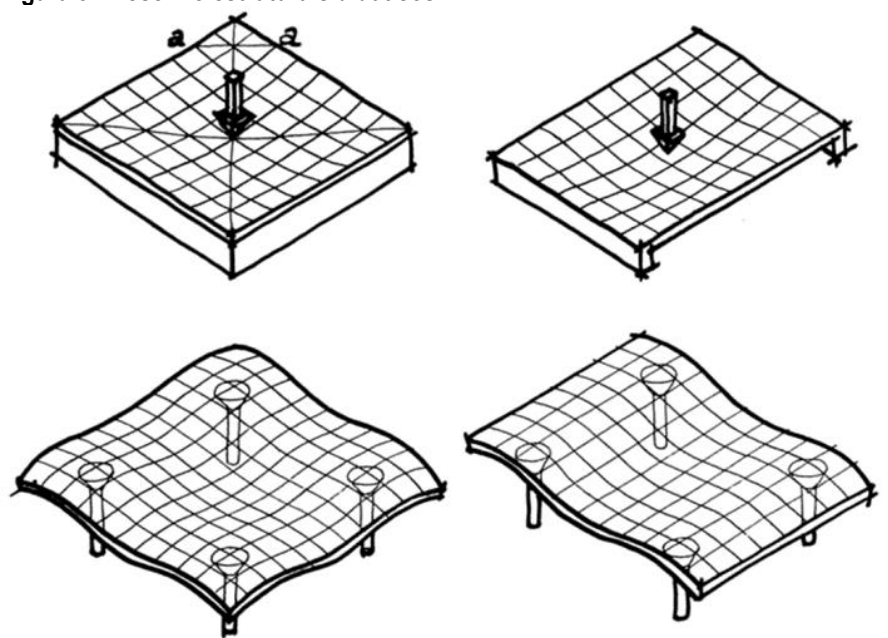

Fonte: Torroja, 1957

Uma das vantagens do uso de modelos tridimensionais qualitativos é a sua capacidade de adaptação a mudanças de condições ou atuações na estrutura proposta (OLIVEIRA, 2008), pois podem ser concebidos para refletir o comportamento de toda uma gama de sistemas similares. Seguindo esta premissa, Rodrigues e Hermida (2006) utilizaram barras e placas de EVA para compor um conjunto extenso de modelos qualitativos, capazes de cobrir uma grande diversidade de soluções estruturais (Figura 4), que buscavam a "percepção do comportamento estrutural por meio da observação das configurações deformadas dos elementos" (RODRIGUES; HERMIDA, 2006, p.20)
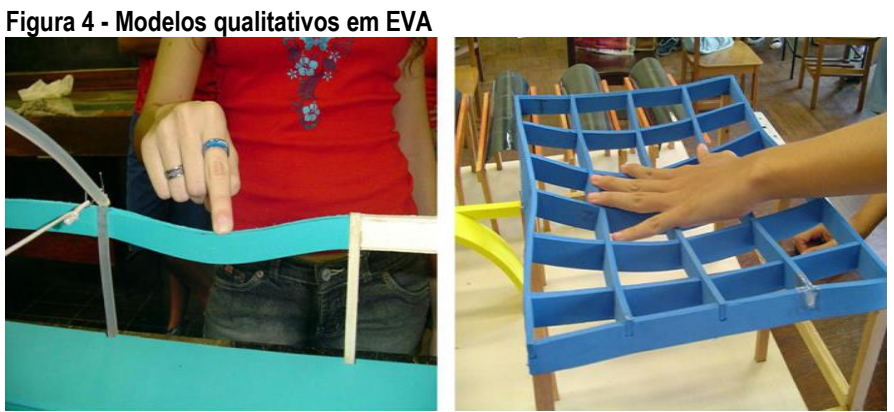

Fonte: Rodrigues e Hermida (2006)

Estes modelos buscavam permitir a compreensão e análise do comportamento dos sistemas de maneira simples e intuitiva. Entretanto, segundo Saramago (2011), apesar de se mostraram bastante eficientes para a compreensão intuitiva do comportamento das peças, não permitem uma clara visualização das regiões tracionadas e comprimidas e possuem uma limitada flexibilidade de recombinação dos esquemas: ainda que o conjunto seja composto de diversos modelos, simulando um grande número de experimentações.

Para facilitar a percepção das zonas tracionadas e comprimidas, Allen e Zalewski (2010) utilizaram uma escala graduada desenhada diretamente em uma barra de espuma, assim, podemos visualizar a deformação da peça, além de, pela aproximação ou do afastamento entre as linhas marcadas ao longo da peça, identificar as zonas sujeitas à tração ou compressão (Figura 5).

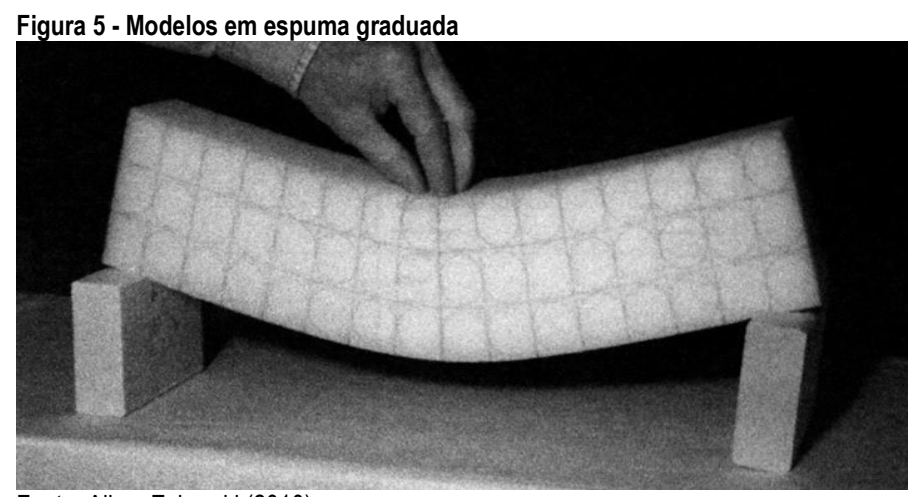

Fonte: Allen; Zalewski (2010).

Com objetivo similar, Pravia e Orlando (2001) desenvolveram um sistema de anéis flexíveis, utilizados nas barras de treliças, que permitem a identificação do tipo de esforço a que está submetida cada barra, compressão ou tração, além de permitir observar comparativamente as barras mais ou menos solicitadas, através da intensidade da deformação percebida nos anéis (Figura 6).

Figura 6 - Modelos de treliças planas com anéis flexíveis
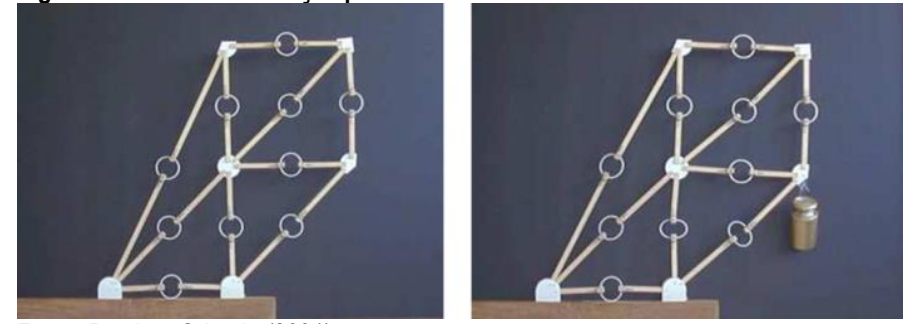

Fonte: Pravia e Orlando (2001).

A partir da percepção das limitações e potencialidades destes sistemas, Oliveira (2008), desenvolve o Kit Mola, um sistema configurável que utiliza molas no lugar das barras de uma estrutura. Esta conformação permite a visualização tanto das deformações por flexão quanto das condições de tração e compressão nas peças (Figura 7). O Mola possui grande flexibilidade de configurações, permitindo a montagem de um grande número de composições distintas a partir da combinação das peças do kit. Também permite, com a ajuda de diversos conectores acessórios, a experimentação das diferentes possibilidades de uma estrutura, a través da alteração dos apoios e engastes entre as diferentes peças do conjunto (Figura 8). 
Figura 7 - Montagem com o Kit Mola e a identificação das zonas tracionadas e comprimidas de uma estrutura.
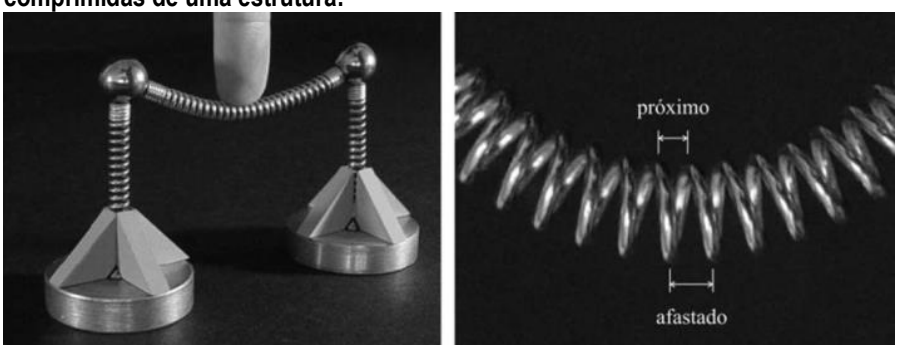

Fonte: Oliveira (2006)

Figura 8 - Montagem em pórtico com o Kit Mola, utilizando acessórios para enrijecer os engastes

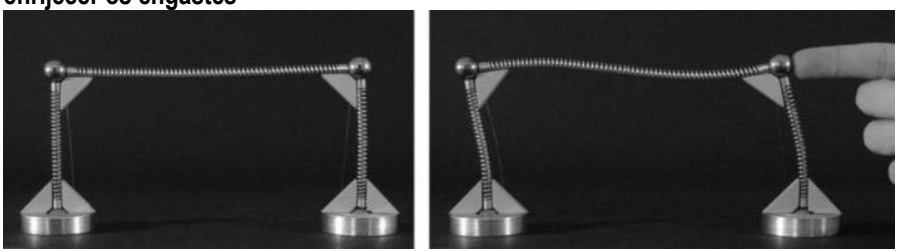

Fonte: Oliveira (2006)

A proposta é que a Maquete Estrutural possa ser utilizada em uma primeira etapa, de experimentação, onde exista apenas a preocupação com o estudo qualitativo, dando ênfase ao aspecto intuitivo, para que posteriormente sejam aprofundados e aplicados os conhecimentos teóricos de cálculo (OLIVEIRA, 2006, p. 49).

Entretanto, a rigidez necessária para a estabilidade do modelo tornou a diferenciação entre tração e compressão bastante sutil e o perfil circular e homogêneo das barras não permite que sejam levados em consideração os efeitos de forma e dimensão das peças no comportamento das estruturas montadas.

Apesar das limitações, a flexibilidade de montagens e engastes, permite uma experimentação ampla e uma percepção bastante intuitiva dos sistemas montados, entretanto, o número restrito de peças e o elevado custo do conjunto se tornam fatores restritivos de sua ampla utilização.

Margarido (2003) também propôs a elaboração de um modelo articulável, com peças simples e padronizadas que se encaixam formando as estruturas (Figura 9). Este modelo também permite a recombinação das soluções em pesquisas exploratórias e a simplicidade das peças parece apontar para o baixo custo da solução.

Entretanto, o problema da ação das dimensões das peças e da visualização das zonas submetidas à compressão ou tração não parece ter sido abordado.

\section{Desenvolvimento de um Modelo Qualitativo}

Segundo Margarido (2003), a maior dificuldade no entendimento intuitivo do comportamento estrutural é fazer as grandezas físicas, facilmente mensuráveis, serem devidamente avalizadas pelos sentimentos humanos.
Figura 9 - Esquema de montagem e peças do modelo proposto por Margarido
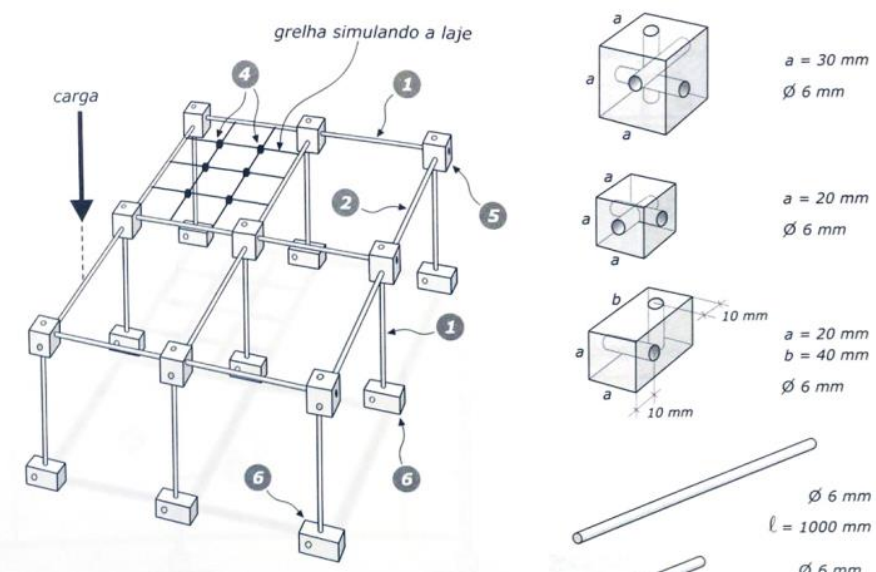

Fonte: Margarido (2003).

Se tomamos o exemplo de uma viga bi-apoiada, precisamos visualizar a flecha $f$ e as rotações $\varphi$, e sermos capazes de perceber como elas variam ao longo da peça e de acordo com as cargas e resistências. Um modelo qualitativo precisa permitir a visualização de que a flecha f é máxima no centro, mas também de que a rotação $\varphi$ é zero no meio da peça, e máxima nos apoios (Figura 10), mas também as regiões comprimidas e tracionadas da estrutura.

Figura 10 - Visualização das deformadas através de modelos

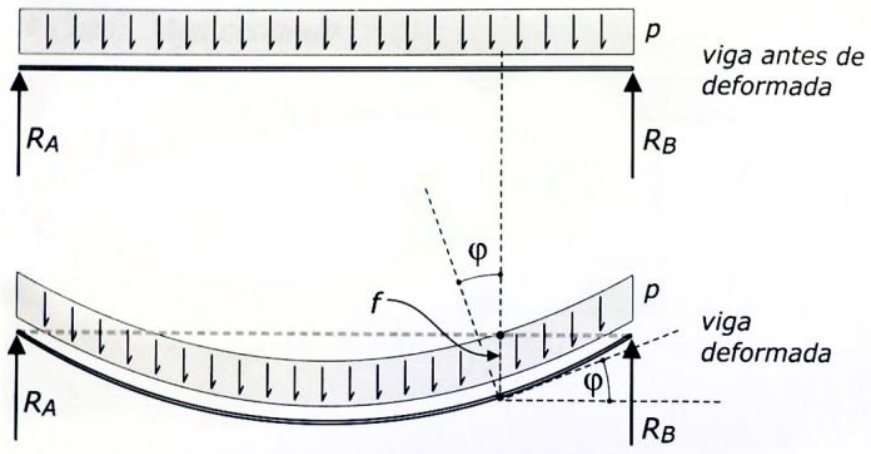

Fonte: Margarido (2003).

Neste sentido, um modelo didático qualitativo precisa permitir uma clara visualização das deformações provocadas pelos esforços a que uma estrutura é submetida. Ou seja, deve ser capaz facilitar a compreensão da atuação dos esforços nas peças e no conjunto e transmitir conceitualmente a lógica interna e os padrões de comportamento de uma estrutura.

Deste modo, buscamos construir um modelo que mantivesse as características de simplicidade de uso e montagem, com custo reduzido, e que fosse capaz de demonstrar as deformações e reações da estrutura, permitir a visualização das áreas submetidas à tração ou compressão e, que ao mesmo tempo, fosse flexível o 
bastante para permitir uma ampla experimentação dos sistemas.

O modelo foi desenvolvido a partir de dois materiais distintos para que cada um pudesse trabalhar um componente da relação tração-compressão. Não por uma mimetização do conjunto concreto-aço, mas como processo de evidenciação dos esforços.

Assim, os primeiros croquis já traziam esta proposta, mas inicialmente montada a partir de um conjunto de placas e elásticos trespassando toda a peça (Figura 11). Mas logo percebemos que esta solução trazia o problema de enrijecer o conjunto, dificultando as alterações formais e de dimensões das peças.

Figura 11 - Primeiros croquis de concepção do modelo
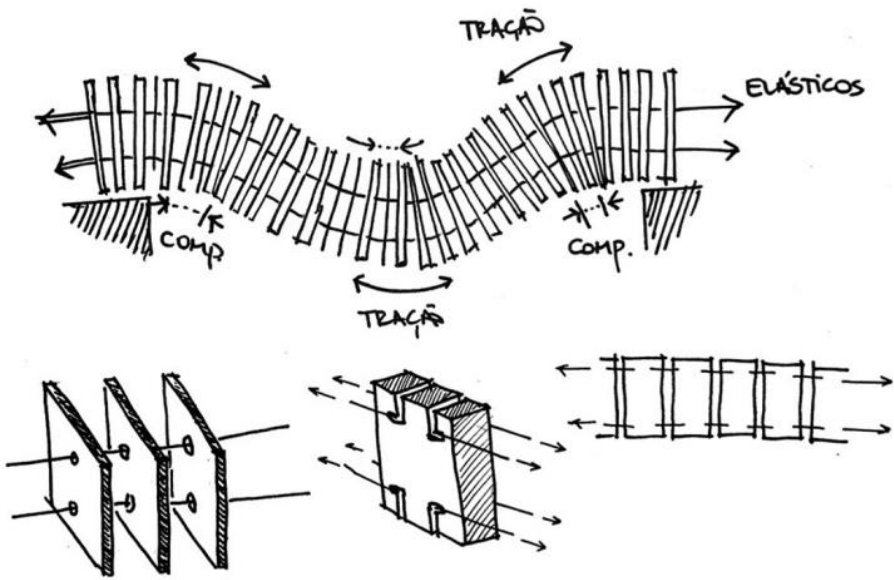

Fonte: Os autores.

Por fim, optou-se pela utilização de pequenos blocos, unidos pontualmente por elásticos. Esta solução privilegia a possibilidade de alteração e recomposição das peças, e ainda traz a possibilidade de alteração pontual da resistência do conjunto a partir da substituição dos elásticos.

O modelo proposto foi pensado a partir da combinação de peças simples e configuráveis, de maneira a permitir o ajuste de fatores formais, dimensionais e de resistência.

A primeira proposta foi desenvolvida em blocos de EVA, presos por elásticos (Figura 12), para permitir a demonstração clara das zonas sujeitas a tração e compressão. Entretanto os protótipos iniciais apresentaram um comportamento um pouco irregular e a dificuldade de obter blocos com dimensões precisas acabou por dificultar a evolução do modelo em EVA.

Após esta experiência, elaboramos um modelo a partir do uso de pequenos blocos rígidos de MDF cortados à laser e unidos por tendões elásticos (Figura 13). Esta solução foi adotada pela precisão nas dimensões dos blocos e pelo comportamento regular que a homogeneidade do modelo trazia.
Figura 12 - Os primeiros protótipos em EVA

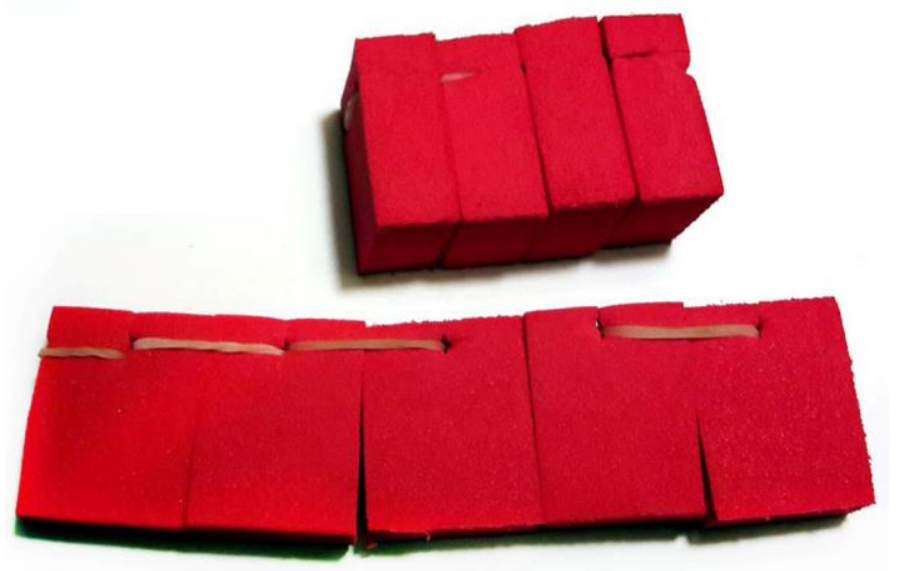

Fonte: Os autores.

Desta forma, para o primeiro protótipo apresentado, utilizamos um grupo de quatro blocos básicos com alturas entre 10 e $25 \mathrm{~mm}$, selecionados a partir das primeiras experiências com alguns modelos básicos (LOBOSCO, 2017). Estas unidades, unidas por meio de elásticos ortodônticos formam as peças a serem estudadas. A existência de conectores fazendo a transição entre dimensões distintas busca permitir a variação dimensional dentro de uma mesma peça (Figura 13). Figura 13 - Os quatro tamanhos dos blocos do modelo e os conectores de
transição

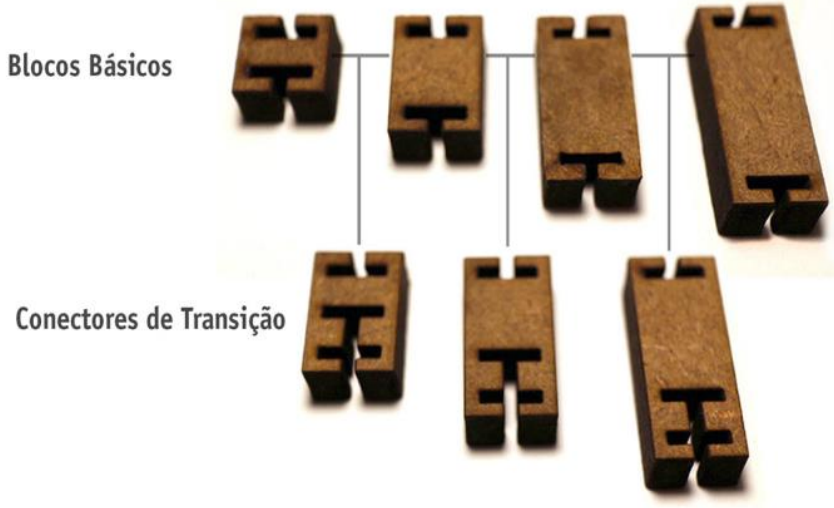

Fonte: Os autores.

Esta situação nos permite uma eficiente representação das deformações e reações, adicionalmente o uso de elásticos ortodônticos permite o ajuste da resistência das peças de maneira bastante flexível, pois podem ser substituídos pontualmente e são facilmente encontrados, com três resistências distintas para cada tamanho além da possibilidade de utilização de cores distintas para facilitar a identificação.

Esta concepção foi elaborada para permitir a montagem, de diversas configurações estruturais distintas e que estas configurações pudessem ser testadas com diferentes dimensões - alterando o tipo de bloco aplicado - e com diferentes resistências - a partir do uso dos diferentes elásticos - em pontos específicos da estrutura. 
Outros formatos e dimensões de blocos foram testados, mas acabaram sendo descartados por terem a montagem mais complexa, por não apresentar um comportamento adequado à visualização dos fenômenos ou mesmo pela dificuldade de corte dos blocos.

\section{O Modelo Proposto}

O modelo foi concebido a partir dos ensaios iniciais realizados em Lobosco (2017), buscando um conjunto com um número reduzido de peças, de modo a facilitar seu uso e produção, mas ao mesmo tempo permitir montagens diversificadas a partir da recombinação de suas unidades.

As peças que compõem o modelo foram cortadas à laser a partir de placas de MDF de $6 \mathrm{~mm}$ de espessura, conectadas com elásticos ortodônticos intraorais de látex, com diâmetro interno de $1 / 8$ " e resistências pesada e média, de acordo com a montagem desejada.

Para os testes iniciais, montamos um conjunto de barras lineares, a partir de cada uma das quatro dimensões básicas de peças do conjunto, que compõem a base dos ensaios realizados a seguir (Figura 14).

Figura 14 - As quatro peças básicas montadas, a partir dos diferentes tamanhos de peças do modelo
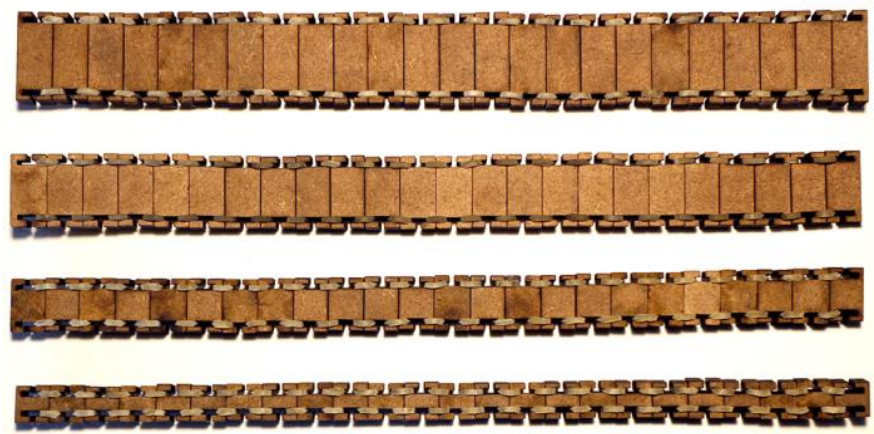

Fonte: Os autores.

\section{Montagens Lineares}

A partir das peças criadas foram montadas vigas lineares contínuas biapoiadas, com blocos de mesmo tamanho e elásticos fortes em toda a extensão da peça (Figura 15).

Figura 15 - Comparação entre as diferentes dimensões de montagens possíveis
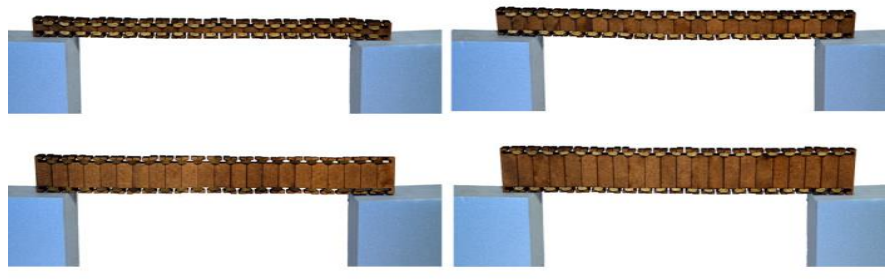

Fonte: Os autores

Ao aplicarmos a carga, podemos ver que o modelo reage, permitindo visualizar as regiões sob tração, pelo alongamento dos elásticos, e o desenho esquemático de sua deformação (Figura 16). Os diferentes tamanhos de blocos que o modelo prevê, permite visualizar a influência da dimensão na resistência final das peças. No ensaio da Figura 16, utilizamos elásticos de mesma resistência e aplicamos a mesma carga em cada uma das montagens. Assim podemos perceber as reações bastante distintas da estrutura, devido apenas à dimensão da peça.

Figura 16 - Comparação da aplicação da mesma carga em vigas biapioadas com dferentes dimensões

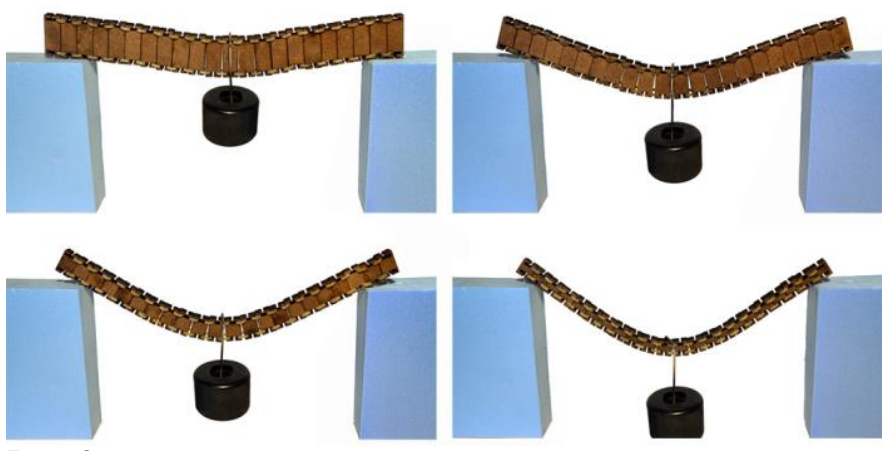

Fonte: Os autores.

Através destas montagens podemos observar claramente as zonas submetidas aos maiores esforços, portanto, podemos experimentar a flexibilidade do modelo, compondo uma nova montagem, com blocos de maior dimensão nas zonas submetidas aos maiores esforços e, no sentido inverso, blocos menores nas zonas sob esforços menos intensos. Nesta montagem experimentamos também engastes nas extremidades, o que aumentou a rigidez do conjunto exigindo também uma carga maior para visualizar os efeitos na peça. (Figura 17).

Figura 17 - Comparação da aplicação da mesma carga em uma viga biapioada com dimensões variáveis

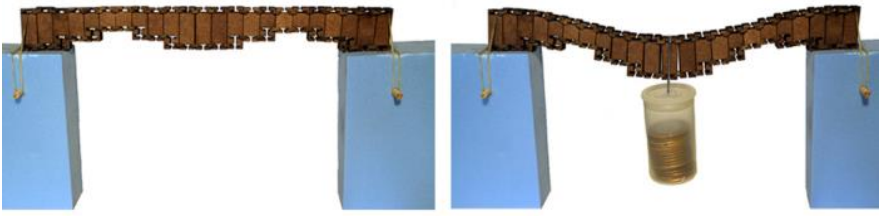

Fonte: Os autores.

Com esta montagem podemos visualizar o efeito do da dimensão na resistência de uma peça. Assim, se compararmos esta montagem com a primeira da Figura 16, podemos verificar que seu comportamento é bastante similar, apesar do grande alívio de material e peso que esta construção proporciona ao conjunto.

\section{Montagens em pórticos}

No processo de articulação das unidades básicas em diferentes configurações apresentamos as montagens em pórticos e arcos buscando, não apenas identificar os limites da flexibilidade que o conjunto apresenta (LOBOSCO, 2017), entretanto, para estudar o 
comportamento do modelo nestas situações - ainda que se trate de um modelo destinado ao ambiente de aprendizagem, ou mais especificamente ao entendimento intuitivo do comportamento elementar das estruturas como estas situações envolvem torções e deformações mais complexas, decidimos comparar o comportamento apresentado pelo modelo com uma simulação em computador da mesma estrutura, montada no software SAP2000.

Esta correlação permitiu verificar a fidelidade do comportamento do modelo, de modo a certificar que as simplificações inerentes a um modelo didático em escala reduzida não tenham comprometido a correta visualização das deformações.

A estruturação do modelo em um pórtico pode ser feita simplesmente torcendo as peças situadas nos vértices, para criar os ângulos de 90 graus.

Com as bases engastadas foi possível experimentar a aplicação de cargas verticais e horizontais na estrutura (Figuras 18, 19), assim como seu comportamento quando submetida à torção (Figura 20). Estas estruturas se mostraram bastante eficientes na visualização das deformações.

Figura 18 - Comparação entre a montagem em pórtico com carga vertical e a simulação digital da mesma situação
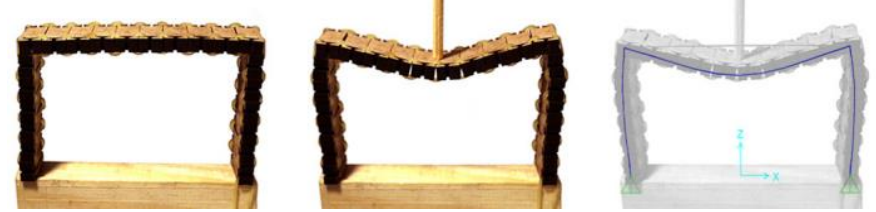

Fonte: Os autores

Figura 19 - Comparação entre a montagem em pórtico com carga lateral e a simulação digital da mesma situação

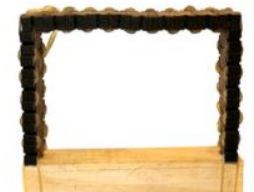

Fonte: Os autores.
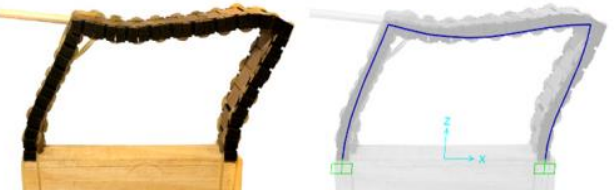

Figura 20 - Comparação entre a montagem em pórtico submetido à torção e a simulação digital da mesma situação

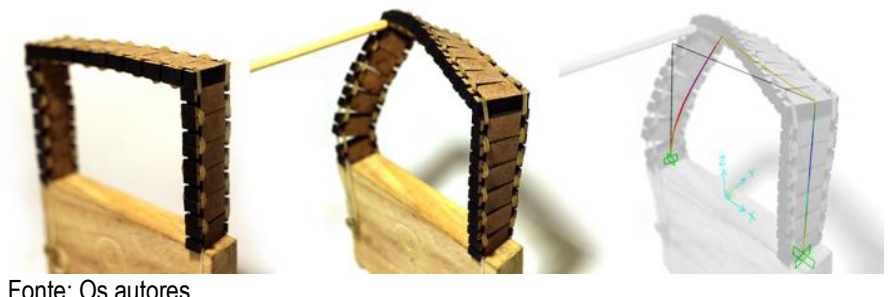

Na situação com carga lateral, é importante observar que, durante os ensaios, o modelo apresentou instabilidade nos engastes superiores que acabavam cedendo, produzindo um comportamento divergente do sistema. Para evitar esta situação, a junção superior precisou ser reforçada. Esta situação aponta para a necessidade de desenvolvimento de algumas peças acessórias para a construção precisa de conexões rígidas.

A partir dos ensaios, podemos os perceber que as montagens permitiram boa visualização das deformações e dos momentos fletores atuando tanto nos pilares quanto nas vigas, além da identificação das zonas sob tração e compressão nos sistemas.

Nas montagens em pórticos também foi possível perceber a visualização situações de torção, ocorridas quando a carga era aplicada transversalmente à montagem (Figura 20).

\section{Montagens em arcos}

A partir da construção básica das peças lineares também foi possível realizar montagens em arcos e outras formas curvas, apoiados em bases engastadas (Figura 21).

Figura 21 - Comparação entre a montagem em pórtico submetido à torção e a simulação digital da mesma situação

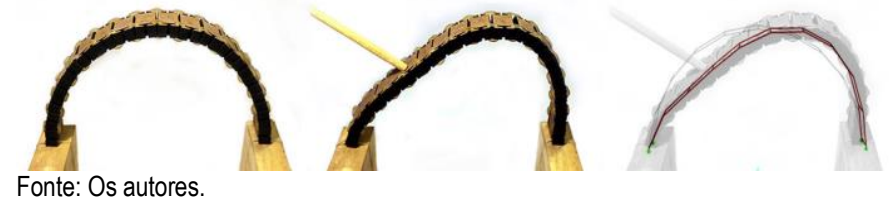

Estas estruturas também se mostraram bastante eficientes na visualização das deformações, simulando um comportamento de cascas e arcos armados, tanto com cargas aplicadas lateralmente, quanto transversalmente. Neste caso, evidenciando as condições de torção da estrutura (Figura 22).

Figura 22 - Comparação entre a montagem em pórtico submetido à torção e a simulação digital da mesma situação
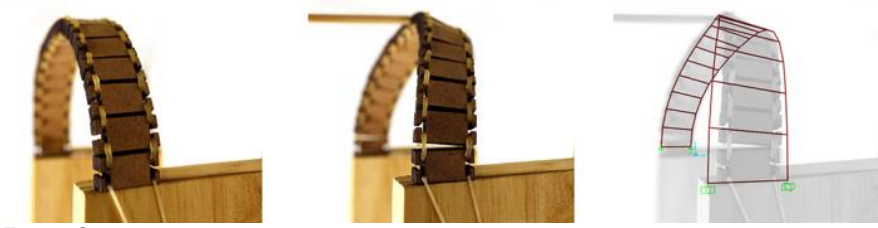

Fonte: Os autores.

\section{Avaliação e desenvolvimento do protótipo}

Os resultados iniciais se mostraram promissores, percebemos que o modelo permitia uma boa visualização das deformações, inclusive torções, e era capaz de promover um bom contato inicial para a compreensão do comportamento das estruturas.

Entretanto, identificamos que o modelo, apesar de permitir boa visualização das regiões submetidas à tração, ainda não apresentava uma visualização equivalente para as regiões sob compressão além de não apresentar 
flexibilidade suficiente para permitir diferentes configurações estruturais.

Neste sentido desenvolvemos um segundo conjunto de peças, a partir da unidade básica de $20 \mathrm{~mm}$, com a inserção de espaçadores em EVA de $5 \mathrm{~mm}$ entre cada unidade de MDF (Figura 23).

Figura 23 - Configuração final da viga com espaçadores em EVA e um exemplo da visualização das regiões submetidas à tração e compressão
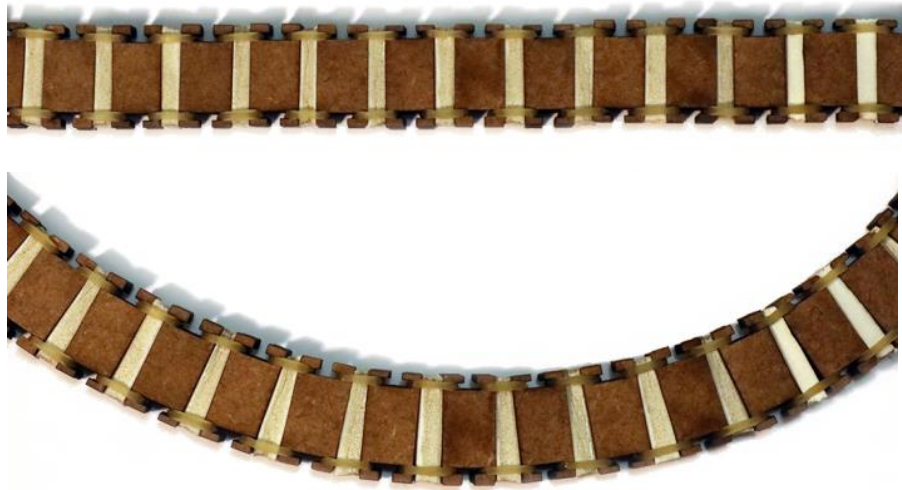

Fonte: Os autores.

Esta configuração, alternando peças em MDF e EVA, não apresentou o mesmo comportamento irregular que o conjunto inicial, feito apenas em EVA. A interação entre a rigidez do MDF e a flexibilidade do EVA se mostrou eficaz na execução das estruturas além de permitir uma eficiente visualização das regiões submetidas tanto à tração quanto à compressão (Figura 23).

Em seguida, buscamos o desenvolvimento de novas peças e conexões, que permitissem a montagem de diferentes configurações estruturais a partir do conjunto.

A partir do bloco básico de $20 \mathrm{~mm}$, a construção dos pilares seguiu o mesmo princípio de conexão por elásticos ortodônticos e espaçadores em EVA, entretanto, nesta situação utilizamos elásticos em látex, com diâmetro interno de $3 / 8$ ", na resistência média e posicionamos as unidades horizontalmente, de modo a garantir uma maior estabilidade do conjunto, principalmente em relação aos esforços de flambagem.

Para permitir a diversidade de montagens do conjunto, criamos conectores capazes de unir as vigas nos dois sentidos, além de conectá-las aos pilares. Estas novas peças funcionam unicamente através de encaixes, para garantir a simplicidade do conjunto (Figura 24).

Deste modo, o modelo final ficou composto de unidades em MDF e EVA, todas com 5mm de espessura e cortadas a laser, de modo a manter a simplicidade de fabricação e distribuição do conjunto (Figura 25).
Figura 24 - Vista explodida das novas conexões, mostrando o sistema de encaixe com as outras peças do conjunto

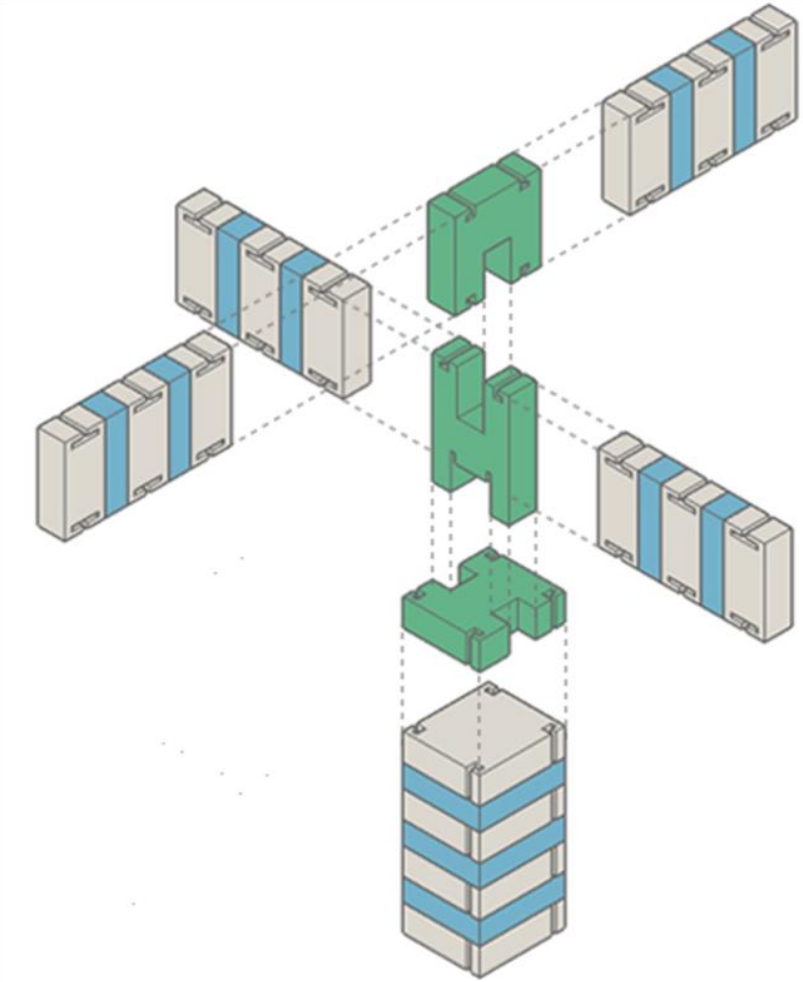

Fonte: Os autores.

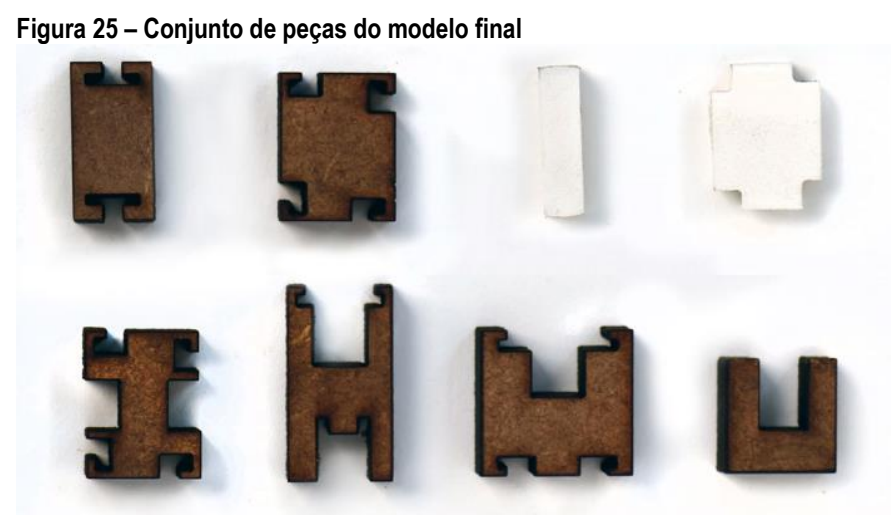

Fonte: Os autores.

Por fim, para permitir a realização das montagens, e estruturar o conjunto, criamos uma base, cortada a laser em MDF de $3 \mathrm{~mm}$ de espessura, com conexões modulares, permitindo diferentes posicionamentos para cada uma das peças. A base possui perfurações que permitem a passagem de um conector em "U" que se fixa com a base dos pilares criando um engaste.

\section{Montagens em pórticos lineares}

A partir do novo conjunto de peças criadas, elaboramos as primeiras montagens em conjuntos trilíticos lineares. Estas montagens apresentaram uma boa visualização das deformações, permitindo a identificação das regiões submetidas à compressão, assim como daquelas à tração, mas também forma capazes de demonstrar o 
encaminhamento das forças ao longo do conjunto estrutural (Figura 26).

Figura 26 - Comparação entre as montagens em pórticos com e sem carga vertical
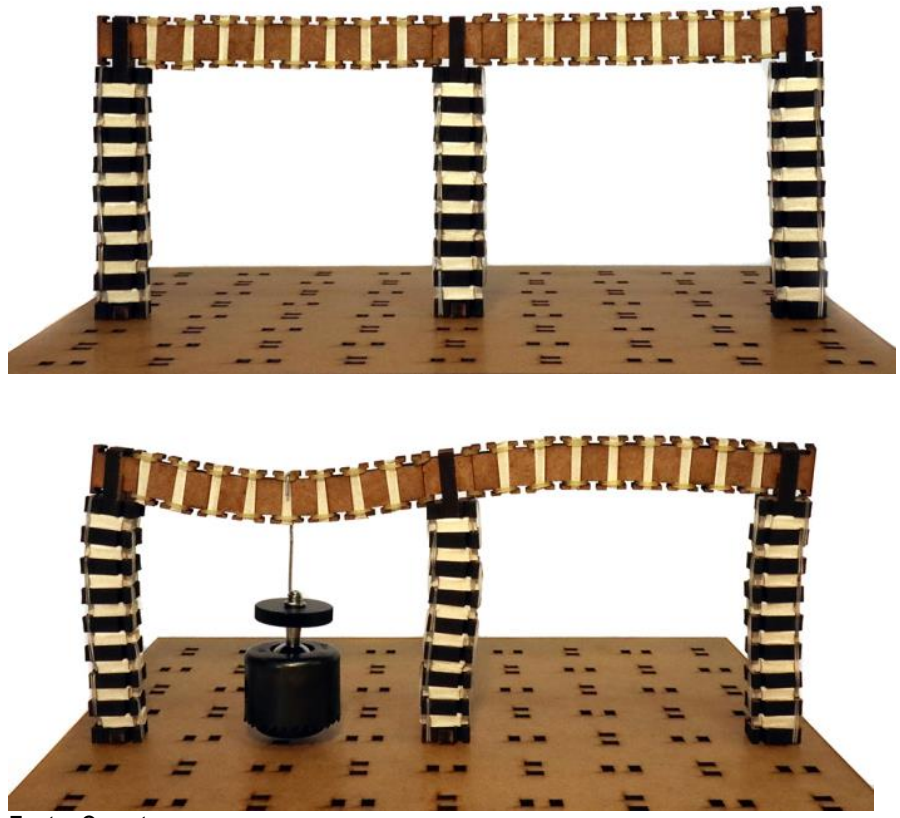

Fonte: Os autores.

\section{Montagens Tridimensionais}

A partir dos resultados positivos obtidos nas montagens planas, experimentamos o comportamento do modelo em composições tridimensionais para analisar os diferentes tipos de montagens que poderiam ser obtidos com as conexões em encaixe.

Deste modo, testamos as diferentes configurações de montagem do modelo e sua resposta à aplicação de cargas verticais afim de analisar o comportamento do modelo na representação das deformações e reações estruturais.

Esta nova configuração do modelo demonstrou uma significativa evolução na flexibilidade das montagens, permitindo a alteração do comprimento e posicionamento das vigas, além das alturas e número de pilares.

Nestas configurações, o modelo demonstrou uma boa visualização tanto das deformações quanto do encaminhamento das forças no conjunto estrutural, visíveis através das deformações dos pilares e da torção das vigas adjacentes (Figuras 27 e 28).

Por fim, experimentamos a flexibilidade e o comportamento do modelo em situações com balanços, a partir de duas configurações básicas: com vigas curvas ou retilíneas (Figura 29).

Nestas configurações, testadas com carregamento vertical e horizontal, podemos perceber que o modelo permite a correta visualização das deformações, evidenciando não apenas os momentos fletores atuantes em todo o conjunto, mas também as situações de torção apresentadas pela estrutura.

Figura 27 - Comparação entre as montagens em pórticos tridimensionais com e sem carga vertical em uma das vigas externas.
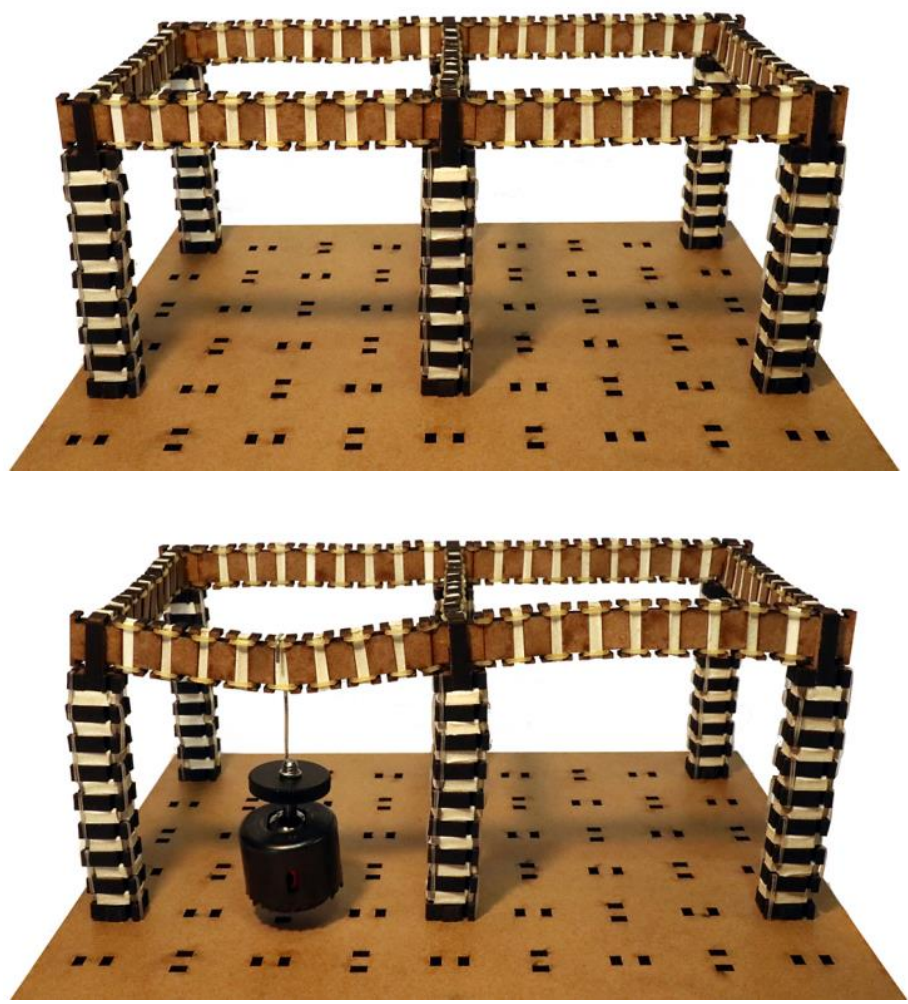

Fonte: Os autores.

Figura 28 - Montagem em pórticos tridimensionais com apicação de carga vertical em viga interna.

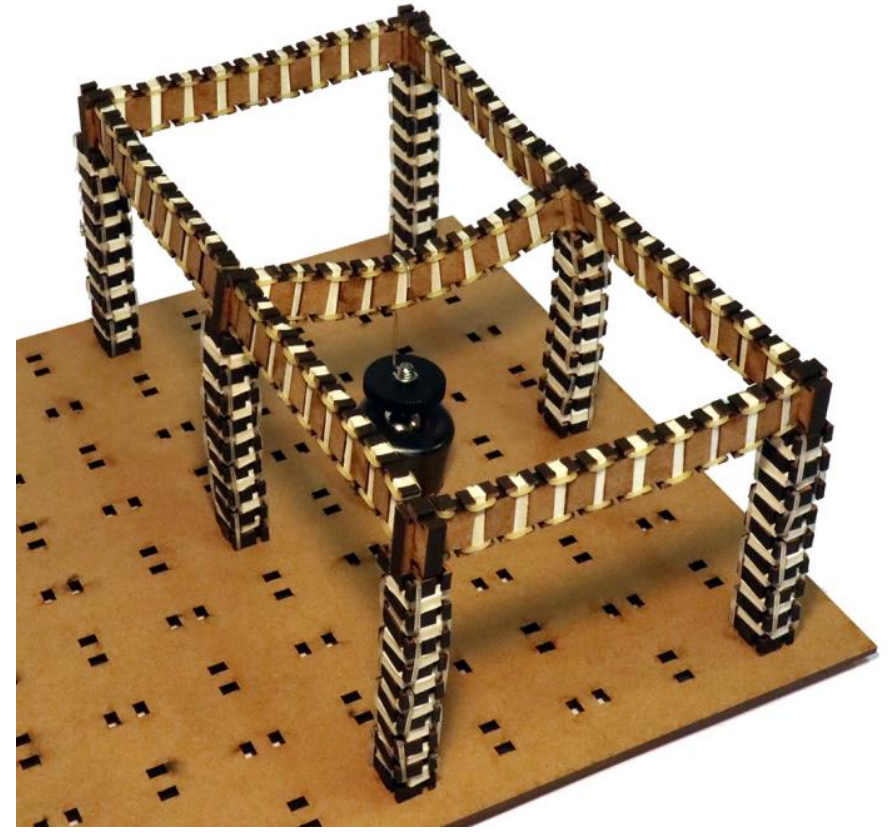

Fonte: Os autores. 
Figura 29 - Comparação das montagens com balanço, com e sem a aplicação de cargas verticais e horizontais
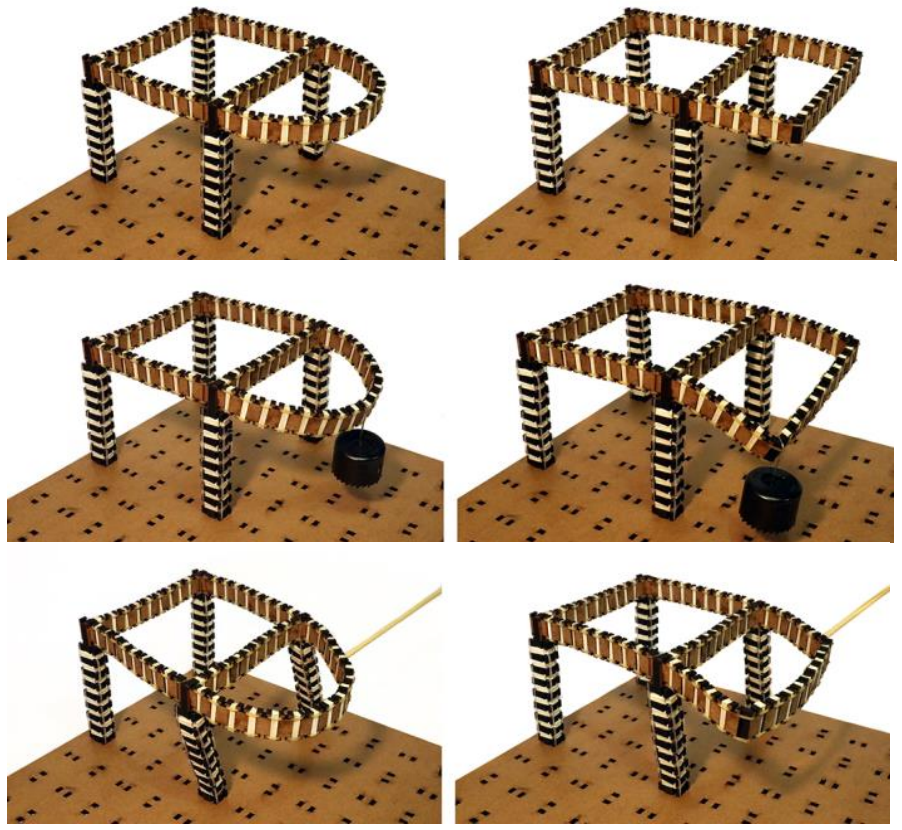

Fonte: Os autores.

Com isso, percebemos que esta nova configuração do modelo apresenta flexibilidade suficiente para reproduzir um significativo número de montagens estruturais além de permitir a visualização das deformações apresentadas ao longo de toda a estrutura, diferenciando as situações de tração, compressão e torção.

\section{Conclusão}

A compreensão dos padrões de funcionamento das estruturas: suas deformações, a influência da forma e das dimensões das peças no comportamento e a maneira de resistir aos esforços são de essencial importância para o processo de concepção estrutural.

Neste sentido, os modelos qualitativos didáticos são ferramentas essenciais tanto para o desenvolvimento de um sentimento intuitivo do comportamento estrutural, quanto como ferramenta de aprendizagem, por facilitar a correlação entre o fenômeno mecânico experimentado no modelo reduzido e o desenvolvimento da concepção estrutural através dos modelos numérico-computacionais.
Mais do que a simulação numérica estrutural, acreditamos que é a experiência vivenciada destas situações, em escala reduzida ou real, que permite a construção de um universo referencial, de comportamentos e soluções, que formarão a base conceitual do profissional.

De modo geral, os modelos mais simples, analisados aqui, conseguiam resolver perfeitamente apenas problemas pontuais e os conjuntos mais estruturados foram capazes de cobrir uma grande gama de experimentos intuitivos, mas também apresentavam algumas limitações específicas: O kit Mola possui peças com tamanhos rígidos e não se mostrou eficiente na percepção da influência das dimensões no comportamento; já os experimentos de Rodrigues e Hermida (2006) não apresentam a possibilidade de articulação e recombinação das peças criando soluções alternativas.

O modelo proposto apresentou um resultado bastante positivo, tanto em termos de visualização dos fenômenos quanto em praticidade e flexibilidade de montagens. Percebemos ser possível, com um pequeno número de peças, montar uma grande variedade de possibilidades estruturais distintas e ainda manter a flexibilidade desejada.

Evidentemente o modelo aqui desenvolvido também apresenta suas limitações, afinal todo modelo traz simplificações no seu processo que acabam se traduzindo em dificuldades. Entretanto a proposta vem se juntar ao universo existente, complementando as possibilidades e fechando lacunas na oferta de um ferramental de aprendizagem completo e amplo.

Também buscamos com este modelo atacar outro problema: os experimentos existentes são confeccionados especificamente para a disciplina em que são aplicados no caso de Rodrigues e Hermida (2006) ou possuem um custo elevado, como o Kit Mola, o que reduz a difusão destas ferramentas e o acesso a ela pelos estudantes. A proposta de desenvolvimento deste modelo prevê a sua distribuição livre, através de arquivos .dxf contendo o desenho das peças para serem cortadas a laser, e um manual explicativo contendo a especificação dos elásticos e instruções e esquemas de montagem das peças.

\section{Referências}

ALLEN, E.; ZALEWSKI, W. Form and Forces: designing efficient, expressive structures. New Jersey: Wiley, 2010.

ENGEL, E. Sistemas de Estruturas. Barcelona: Gustavo Gili, 2001.

EVANS, P.; SILVER, P.; MCLEAN, W. Sistemas Estruturais. São Paulo: Blucher, 2009. 
FRANCO, M. O papel da história no ensino da teoria das estruturas. In: ENCONTRO DE PROFESSORES DE ESTRUTURA PARA ESCOLAS DE ARQUITETURA, 1., São Paulo, 1974. Anais... São Paulo: FAUUSP, 1974. p.1-7.

HARRIS, H; SABNIS, G. Structural Modeling and Experimental Techniques. Boca Raton: CRC Press, 1999.

HOSSDORF, H. Model analysis of structures. New York: Van Nostrand Reinhold, 1974.

LOBOSCO, T. Modelos Didáticos para Exploração e Compreensão Estrutural. In: ENCONTRO NACIONAL DE ENSINO DE ESTRUTURAS EM ESCOLAS DE ARQUITETURA, 3,. Ouro Preto, 2017. Anais... Ouro Preto: UFOP, 2017. p.796-809.

MARGARIDO, A. Fundamentos de Estruturas. São Paulo: Zigurate, 2003

NERVI, P. L. Lenguage arquitectónico. Buenos Aires: FADU, 1951.

OLIVEIRA, M. Modelo Estrutural Qualitativo para Pré-Avaliação do Comportamento de Estruturas Metálicas. 2008.172 f. Dissertação (Mestrado em Engenharia Civil), Escola de Minas, Universidade Federal de Ouro Preto, Ouro Preto, 2008.

PRAVIA, Z.; ORLANDO, D. Modelos qualitativos de treliças planas: Construção e aplicação no ensino da análise e comportamento estrutural. In: CONGRESSO BRASILEIRO DE ENSINO DE ENGENHARIA, 29., Porto Alegre, 2001. Anais... Porto Alegre: PUC-RS. 2001. p.9-14.

RODRIGUES, P. F.; HERMIDA, A. Modelagem de elementos básicos de estruturas para a análise qualitativa do comportamento estrutural. Revista de Ciência e Tecnologia, Nova Iguaçu, v. 6, n. 1, jun. 2006.

SARAMAGO, R. C. P. Ensino de estruturas nas escolas de Arquitetura do Brasil. 2011. Dissertação (Mestrado) - Escola de Engenharia de São Carlos, Universidade de São Paulo, São Carlos, 2011.

SALVADORI, M. The Art of Construction: projects and principles for beginning engineers \& architects. Chicago: Chicago Review Press, 1990.

REBELlO, Y. A Concepção Estrutural e a Arquitetura. São Paulo: Zigurate, 2000.

SCHODEK, D.; BECHTHOLD, M. Structures. Noida: Person India, 2015.

TORROJA, E. Razón y Ser de los Tipos Estructurales. Madrid: Consejo Superior de Investigaciones Científicas, 1957.

\footnotetext{
1 Tales Lobosco

Arquiteto e Urbanista. Doutor em Arquitetura e Urbanismo pela Universidade Federal da Bahia (PPG/AU). Professor Adjunto da Escola de Arquitetura da UFMG. Rua Sergipe, 781 ap. 303, Belo Horizonte, MG, Brasil, 30130-171

\section{${ }^{2}$ Débora Carvalho Câmara}

Graduanda em Arquitetura e Urbanismo. Aluna de Iniciação Científica da UFMG. Rua Indiana, 322 ap. 301, Belo Horizonte, MG, Brasil, 30421-379
} 